\title{
Smart Tourism via Smart Phone
}

\author{
$\mathrm{Pu} \mathrm{Liu}{ }^{1,2, *}$ and Yuan $\mathrm{Liu}^{2}$ \\ ${ }^{1}$ Beijing Jiaotong University, No.3 Shangyuan Cun, Haidian District, Beijing, China \\ ${ }^{2}$ Jiangnan University, No.1800 Lihu Avenue, Binhu District, Wuxi, China \\ ${ }^{*}$ Corresponding author
}

\begin{abstract}
Smart tourism of Chinese cities try to provide tourists with all services and businesses via smart phones. This article analyzes the relationship between the smart tourism and smart city; explores the architecture of a smart tourism system, the technology application and supporting platform; focuses on solutions via smart phones; and discusses problems, challenges and future trends in the process of developing smart tourism.
\end{abstract}

Keywords-smart tourism; smart city; smart phone; mobile communication; Internet of things; cloud computing; ambient intelligence

\section{INTRODUCTION}

Internet of things, cloud computing, big data and mobile internet brings the "smart" trend which is typified by terms of smart planet and smart city. Relevant academic reports are increasing these years. Smart technology application is practiced in China in a large scale. It is put forward by Chinese National Tourism Administration in its Twelfth-five-year Tourism Development Planning as a national strategy that smart tourism is aimed under the national "big tour" formation. At present there are 33 national smart tourism pilot cities among the 290 smart cities in China.

The first section of this article explains the definition, origin, architecture, supporting platform of smart tourism. The next section analyzes why and how the services and businesses of smart tourism provided via smartphones. In the last section problems are drawn out, suggestions are made, concluding with the statement of tourism revolution the smart tourism brings.

\section{SMART TOURISM AND SMART CITY}

The consensus definition of smart tourism does not exist neither in IT industry nor tourism academia. Smart tourism is based on the Internet of things (IoT), cloud computing, mobile communication, artificial intelligence technology. Automatic perception, timely delivery and mining analysis is achieved by embedding sensors in each kind of tourist resources, so various elements involved in tourism get linked, the physical resources and information resources deeply activated and the entire tourism industry chain integrated.

Smart tourism and smart city are closely related. Smart Tourism arises out of the concept of smart city, relies on its infrastructure, and in turn strengthens the linkages of every subsystem of a smart city and the linkages of smart cities so enhance them. Smart tourism can be considered as the application of smart city in the field of tourism, the service objects extending from city residents outwards to tourists. As tourists and city dwellers differ in characteristics and demands, and tours occur not only in the cities, the smart tourism has a broader connotation than the smart city, always involving various fields and spanning various places, also presents more problems of smart cities.

A huge system of smart tourism covers entire tour industry, the basic features including a center (large database storing vast amounts of tourist information and cloud computing servers with powerful computing capability), network (Internet, IoT, communications network), client-side (people travelling or residing in the tourist site who need the smart tourism services), server-side (units or individuals providing services to tourists directly or indirectly, including travel agencies, tourist bureaus, tour guides, hotels, enterprises of the scenic spots and other service providers, departments of government which guarantee the environment, public safety, transportation, disaster protection, health care and quality inspection). Various entities achieve mastery through a comprehensive cooperation to constitute the seamless body of smart tourism. There are four layers in the architecture model: the sensing layer, the network layer, the cloud layer, the application layer, from the bottom to the top. (Figure I)

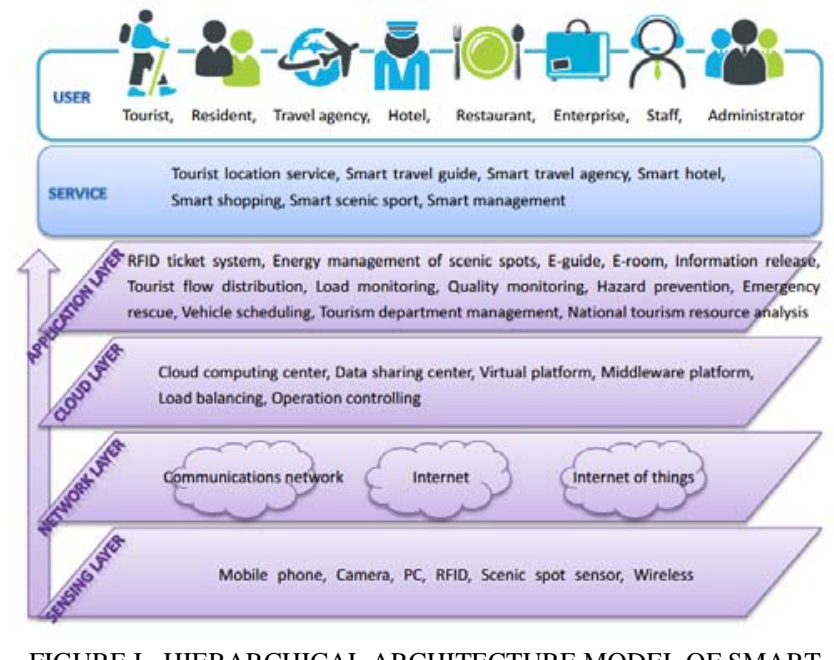

FIGURE I. HIERARCHICAL ARCHITECTURE MODEL OF SMART TOURISM

The first thing is universal linkage. Sensor devices embed in and link objects of all scenery spots, cultural relics, historic sites, public facilities, etc., to a network. Through this realtime perceiving is achieved, on geographies, natural disasters, tracks of tourists, residents and staffs in the tour areas. The 
second is full integration. By the combination of the Internet and the IoT, integrated tour database efficiently enhances the interaction among tourism resources, tourists, local residents, commercial enterprises and administration authorities of tourism. Collaborative work is the third step. Different sectors and systems involved in tourism share information and cooperate, making the best tourism activities and management decisions, predicting and responding to emergencies and disasters timely, aiming to the overall development of the tourism industry in its best condition.

Therefore, smart tourism offers to the tourists of personalized travel services, enterprises of complete marketing platforms, administrators of intelligent management platforms, with better tourism order maintaining, traffic controlling, passenger flow estimating, quality detecting, disaster preventing, emergency handling, real-time tourism resources and environment monitoring. (Figure II)

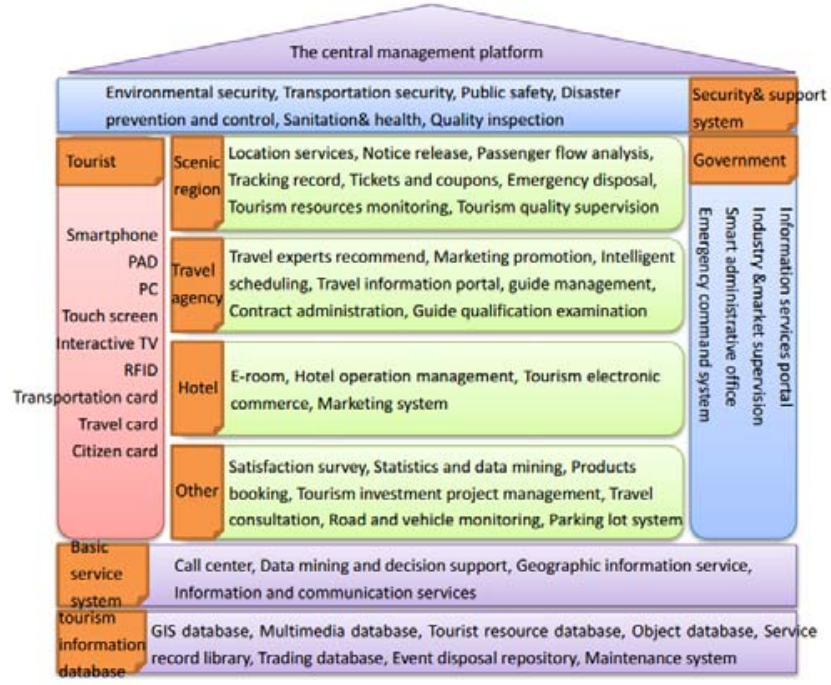

FIGURE II. APPLICATION AND SUPPORTING SYSTEM OF SMART TOURISM

For instance, the tourists' data system acquires dynamic data, the flow and spatial distribution of tourists, as well as monitors carrying capacity of the area, which is in prepared for evacuating any congestion or carrying out emergency rescue, to ensure the quality of tourism also to provide security for tourists. Equally, it will guide tourism enterprises to develop corresponding markets strategy and better products innovation as well as choose long-term cooperative distribution channels, benefited from the actively acquiring, accumulating, analyzing and digging these data for interests and habits of the tourists.

Another example is the scenic resources and environmental monitoring system which conducts comprehensive perception, intelligent recognition, auto-discovery and alarm in time, covering quality of air and water, noise, infrastructure, load level, emergency and anomalies, etc., to prevent and control natural or man-made disasters. It also monitors tourism resources from all aspects of the temperature, humidity, wind erosion, color and luster, which are sensed to the IoT controller so that maintenance and repair can be done promptly.

\section{SMARTPHONES’ SOLUTION FOR SMART TOURISM}

Major cities of smart tourism in China are trying to provide all the services and businesses to tourists via smartphones. The model of "travelling with a smartphone" appears and extends as a template. Examples are smartphone applications "Nanjing Tourist Assistant", "E Lungcheng", "I Xiangshan Travels ", ”Le Youyou”, and "Smart Lushan".

The reason is that smartphones firmly occupy the first position on accessing the Internet in China. Chinese Internet Network Information Center (CNNIC) released that by June 2016 Chinese netizens reached 710 million, while 656 million through mobile phones, accounting for $92.5 \%$ of the total Internet population.

It is also relies on the cloud computing which pushes the limits on mobile applications result from the original storage space and computing power of smartphones. In addition, smartphones usually carry a variety of sensors such as GPS, network positioning and RFID. With the development of location-based services (LBS), mobile location services (MLS), natural language and multimodal interaction (speech, motion or gesture control), smartphones facilitate smart tourism.

From the user's point of view, it brings a lot of convenience to the tourists that a smartphone become the terminal carrier of Smart Tourism, which itself is a combination of PDA, camera, browser, navigator, then adding the function of e-bank, e-map, e-ticket, ID and transportation cards, as so to meet visitors' all need in accommodation, transportation, eating, sightseeing, shopping, entertainment and other activities on the trip. Hence a smartphone can be a tourist navigator, tourist guide, card pack, safety guarantee, care physician to a tourist.

\section{A. Tourist Navigator}

The integration of navigation and the Internet is the future trend of navigation industry. Map, location and related web information are displayed on the interface of a smartphone simultaneously, so that tourists know where it is and what the surrounding details are at any place any time. When the GPS determined the location, the latest information pops up automatically and also updates timely if the position changes. Information includes weather, hot lines, sight spots, traffic condition, congestion, queuing, catering, lodging, shopping, parking lots and available spaces, friends' or tour group members' location, emergency rescue and so on, from which visitors counsel so as to change their travel plans at any time, avoid the crowd rush, choose scenic attractions and solve common problems. By entering keywords of spots, budget expenditure and time, recommended optimal travel routes are generated with related attractions, stations, travel agencies, hotels and restaurants along the way.

\section{B. Tourist Guide}

With a headset, a smartphone is equivalent to a self-help guide. According to the tourists' location, it automatically broadcasts dynamic messages especially the latest announcement released by local authoritative tourism organizations, and sends location information and historic culture background or details in multi-media forms when near 
an interest point. Visitors can also use their smartphones reading the two-dimensional code at that point to obtain such information and according to their needs choose interpretation depth, style and language.

\section{Card Pack}

Equipped with RFID communication capabilities by the Near Field Communication technology (NFC) on its battery, SIM card or shell, the smartphone will upgrade and substitute for all existing metro cards, bus cards, IC cards and smart cards, various payment systems merged together. So that consumption can be done at any place with the NFC readers. All get into one smartphone, severing as the bank card, transportation card, online payment, e-wallet, e-ticket, positioning, authenticating, electronic signing in and other functions, which contains the holder's basic personal information.

\section{Safety Guarantee}

Various emergencies often occur in tourism destinations. Safety is the most important for every tourist. Depending on the RFID and GPS of the tourists' smartphones, rescue force can preliminarily determine the location of missing or unsafe tourists according to the track recorded in the tour region, immediate arrival and effective relief implemented. At the same time the adventure travelers in distress can find the nearest refuge quickly through their smartphones.

\section{E. Care Physician}

Attached wearable devices of sensitive components and behavioral detectors, smartphones record basic data of personal health (blood pressure, blood oxygen, pulse, heartbeats, respiration, temperature, sleep, etc.) and exercise levels (steps, motion intensity, distance, calorie consumption, etc.), analyze and then alert the users that suitably adjustments should be done. (Figure III)

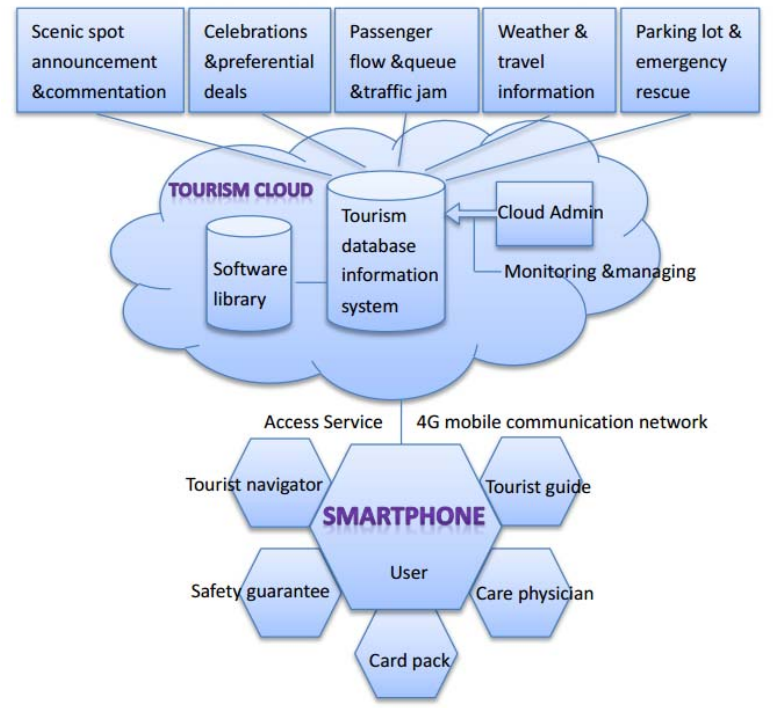

FIGURE III. SMARTPHONE SERVICE AND SOLUTION FOR SMART TOURISM

\section{Challenges AND PROBlems}

Smart tourism involves the use of a variety of new technologies, bringing more threats and challenges because the feature of strong intersectionality, permeability and comprehensiveness of the tourism industry. Obvious problems appear in China now and these challenges may be faced by every city of smart tourism:

Sound security mechanisms have not been established. Security issues present in cooperation with all parties of tourism in the data collection, transmission, distribution and storage. Cloud computing centers highly centralize user information so tourists risk leakage of important personal privacy information when using cloud resources. Ensuring personal information security and identity authentication is the primary challenge when cloud computing applied in smart tourism. The Internet of things has the same defect. An instable, unsafe or unreliable system of the IoT will suffer from virus attack, information theft and damage. Although the threats have not yet become a reality, if security issues are not well resolved, many concepts will remain in mind, not into industry.

Lack of National top-level design and macro guidance causes serious problems currently, which highlights the urgent needs to explore smart tourism in practice under top view. For instance the departments are fragmented; related policies and systems are respective; redundant projects waste funds; hardware is placed too much value on while software ignored; application system is emphasized while information resource neglected; uneven and unbalanced development remains at the technical level and in several areas with a considerable degree of blindness; differentiated and hierarchical building is not implemented with regard for local conditions. They are the results of lack of strategic research, overall planning and systematic design from a national or global perspective without analyzing all kinds of factors and relationships impacting smart tourism construction, determining the longterm goals, or formulating a reasonable target and detailed route.

Relevant laws are inadequate. Across-regional and virtual nature of smart tourism causes problems in legal aspect but current domestic laws and regulations are not formulated in this area. People often face passive circumstances without legal basis once encountering specific problems. Therefore, it is necessary to constitute relevant laws and regulations which should be attached great importance and be improved in a relatively short period of time, escorting rapid development of smart tourism.

Uniform industry standards are absence especially in cloud computing and the Internet of things. Lack of relevant standards in the process of constructing the tourism cloud increases the difficulty of data fusion, considering it covers a very wide range of departments, scenic spots, hotels, travel agencies and transport companies, etc. The IoT does not play greater efficacy in using data and sharing resources because multi-industry standards are not established and applications are not highly integrated. The Internet being able to develop so rapidly throughout the world depends on its uniform standards and coordination mechanisms (network protocols, device port, 
transmission technology, etc.). But they are absence in cloud computing and the IoT now.

Sharing and exchanging is difficult. How to make data shared in managements, services, products, and to avoid "information islands" is a primary challenge faced by smart tourism. Exchanging across departments and regions is still very difficult because tourism enterprises and systems are selfcontained with no valid platform of seamless connection. Scattered resources have not been integrated and improved effectively. Isolated island phenomenon results in repeated investment and waste of manpower, material and financial recourses.

Cooperation needs to be strengthened. Smart tourism should be promoted by the alliance of government, agencies, enterprises, clubs, who reach consensus and go hand in hand to achieve the perfect order state and resources integration. The attempt is trying by Nanjing Tourism Alliance which has included information planning and design units, major telecommunications operators, public card companies, travel website firms and other tourism enterprises, nearly 30 participating members.

The service system is inconvenient to use. The established mechanism of tourism data sharing and services is of single function, not fully considering the needs of tourists. It is not easy to seek in a huge number of search results and obtain all information what exactly the visitor wants. Massive public information grows at fast speed from all levels of tourism bureaus and enterprises, as well as all kinds of professional and non-professional websites. Meanwhile this tourist information often confines to a certain scope cut off from surrounding areas or other cities and the manifestation varies in different places. For instance, in Sichuan province the construction is unified by the Provincial Tourism Bureau, but in Guangdong province it is fragmented by each city. Different style causes serious inconvenience and confusion for those who travel many places during short period having to take time adapt to a completely different set of services system. Concentrated, unified, personalized, and customized information services would provide users with better experience.

Performance of smartphone applications is limited mainly because of following aspects: finite screen size, few keys, weak chip processing power, small storage space and battery capacity. It's also compromised by insufficient network bandwidth. The recent mobile communication network technology has not showed superiority, almost impossible to reach the theoretical speed in the near term. The application covering multiple sets of mobile phone operating system is a focus in current stage. In addition, the threat of mobile payment security is a bottleneck problem urgent to be solved so in that condition the wireless travel market really opens and smart tourism era arrives indeed.

\section{CONCLUSION}

Tourism industry is of the characteristics of informationresource-intensive and communication- technology-dependent, so has higher requirements and has been walking in front of other industries in these respects, which is a direct beneficiary meanwhile a strong promoter of the application of information and communication technology.

Smart tourism is the second revolution in the tourism industry (the first revolution comes from the Internet). It is bound to bring profound changes in the entire tourism industry in that application, integration and innovation of the new generation of information and communication technology conducts in all sectors of the industry. The systematic and intensive revolution will realize effective resources sharing and using, which will change the regulation mode of tourism administration departments, travel behavior and payment mode of the tourists, business mode of tourism enterprises. It will change the organizational models, marketing models, financing models and the structure of the tourism market.

Smart tourism in turn promotes the development of the IoT, cloud computing and other emerging information and wireless communications industry. The smart mobile terminals of smart phones, GPS navigations and other related industries develop rapidly in this atmosphere. Meanwhile, it contributes to the combination of the mobile net, the Internet, the broadcast and television net, as well as the integration of consumer electronics, communication products and computer products.

Smart tourism concentrated on smartphones is a sign that there is an urgent need to unify and integrate into one in largescale, either in technologies, standards, services or policies. Tourism industry becomes the entry point and pioneer in this aspect because of its cross-feature. With next generation mobile communication network, smartphones or other yet unknown ultra-portable terminals will make smart tourism more convenient.

\section{ACKNOWLEDGMENT}

Jiangnan University Independent Scientific Research Program Youth Fund JUSRP11556.

\section{REFERENCES}

[1] M. Hvistendahl "China Pushes the 'Internet of Things'," Science, 2012, vol.336(6086). pp.1581.

[2] D. Wang, P. Sangwon, D. R. Fesenmaier, "The role of smartphones in mediating the touristic experience,” Journal of Travel Research, 2012, vol.51(4), pp.371-387.

[3] U. I. Dong, H. R. Yoon, J. Y. Lee, "Development of the Walking Trail Applicationson GPS-based Smartphone Utilizing the Local Narrative," International Journal of Multimedia \& Ubiquitous Engineering, 2013. pp.26-38.

[4] L. T. Yong, “A collaborative awareness framework for mobile tourist recommender system,” International Conference on Computer Research and Development. IEEE, 2011 pp.329-333.

[5] P. Liu, Z. Peng, "Smart Cities in China,” Computer, 2013, vol.47(10):1. pp.88-99.

[6] P.Liu, Z. Peng, “China's Smart City Pilots: A Progress Report," Computer, 2014, vol.47(10) pp.72-81.

[7] J. Gao, J. Fan, W. Zhang, Z. Xu, X. Sun, "Research on Tourists' Acceptional Behavior of Tourism APP against Smart Tourism Background," Jiangsu Science \& Technology Information, 2016, pp.3241.

[8] L. Dwyer, U. Gretzel, Z. W. Huang, "Special Section: Smart tourism in China,” Journal of China Tourism Research, 2016. pp.112-126. 